\title{
Direct investigation of the adsorption capacities of coconut, date palm and palm kernel shell charcoals commonly found in some North Central States, Nigeria
}

\author{
E. OKORIE ${ }^{1 *}$, N.A. AZAKI ${ }^{1}$ and G. OKORIE ${ }^{2}$ \\ ${ }^{1}$ Department of Science Laboratory Technology, School of Technology, Federal Polytechnic Idah, P.M.B. 1037 \\ Idah, Kogi State, Nigeria. \\ ${ }^{2}$ Technical Department, pollution control/sanitation unit, National Environmental Standards and Regulations \\ Enforcement Agency, Oyo State Field office, OYSROMA House, opposite School of Hygiene, Eleyele, P.M.B. \\ 641, Ibadan, Oyo State, Nigeria. \\ *Corresponding author, E-mail: e.okorieslt@yahoo.com
}

\begin{abstract}
Adsorption capacities of three charcoals were investigated using flame atomic absorption spectrophotometer. Results showed that Palm kernel shell charcoal has the highest adsorption capacity followed by the Date palm and Coconut shell charcoals. For the metals adsorption studied, recoveries ranged from $80.99-83.98 \%$ for $\mathrm{Cu}, 99.10-99.17 \%$ for $\mathrm{Mg}$ and $99.96-100 \%$ for $\mathrm{Pb}$. It was also observed that longer contact time may lead to desorption.

(C) 2013 International Formulae Group. All rights reserved.
\end{abstract}

Keywords: FAAS, charcoal, adsorption capacity, heavy metals.

\section{INTRODUCTION}

Adsorption is the process by which organic molecules are attracted to the surface of an adsorbent. Adsorbents include activated carbon, silica gel, zeolithes and polymers. The most common and widely used adsorbent is activated carbon. The requirement of a good adsorbent is for it to have a high surface area to mass ratio. This will assure the availability of several sites where molecules can attach themselves onto the surface of the adsorbent. Adsorption capacity is the accumulation of solute molecules at the surface of a solid. This capacity is directly proportional to the area of the surface exposed and is dependent on the solute partial pressure and the temperature.
Several research works have tried to prepare activated carbon from bio-waste materials and explored their adsorption capacities (Rifaqat and Fouzia, 2010; Rifaqat et al., 2010). One of the reasons is that adsorption properties of the wastes and biowaste materials available in a particular locality will be helpful for solving the metal contamination problem in a more economical way (Mehmet, 2010). Various adsorbents have been prepared with varying degrees of adsorption capacities for both laboratory and industrial use (Dončo, 2004; Peiyuan et al., 2008; Chien et al., 2004; Linqi et al., 1999; Mizota, 1999; Xu et al., 2003; Wang et al., 2005). Several kinds of adsorbents have been reported for the removal of $\mathrm{H}_{2} \mathrm{~S}$ from the flue 
gas, natural gas and coal-derived gas (Slimane and Abbsasian, 2000). There are reports on the use of transition metals such as $\mathrm{Ni}, \mathrm{Cu}, \mathrm{Co}$ or in some cases noble metals ( $\mathrm{Pt}$ and $\mathrm{Pd}$ ) supported on $\mathrm{Al}_{2} \mathrm{O}_{3}, \mathrm{SiO}_{3}, \mathrm{ZnO}$ or mixture thereof (Velu et al., 2002). Adsorbent have been applied for the treatment of waste water (Hsing-Cheng et al., 2002) and dye removed from solutions (Yavus and Aydin, 2006).

Coconut, date palm and palm trees are grown in the savannah and forest regions of Nigeria. The shells are usually disposable wastes after obtaining probably the more useful endosperm from coconut, the juicy epicarp of the date palm or kernel of the Palm kernel. The vast availability of these agricultural wastes in Nigeria makes them a veritable alternative source of generating activated carbon, and which can save the country scarce foreign exchange on the importation of activated carbon considering its wide use and applications.

In undertaking the research project on direct investigation of adsorption capacities of coconut, date palm and palm kernel shell charcoals, what has been attempted is to establish a possible local source for the production of activated carbon since the adsorption capacity of the primary material for an activated carbon play a major part in determining the ability of the final product to adsorb certain molecular species (Yao et al., 2010; Jung-Nan et al., 2007; Inukai et al., 2004).

The aim of this research is to investigate the adsorption capacities of coconut shell charcoal, date palm shell charcoal, and palm kernel shell charcoal and determine the best suitable and reliable locally source material for the production of a activated carbon as an alternative to the imported products.

\section{MATERIALS AND METHODS Material}

The coconut shells were obtained from Rubochi in the Federal Capital Territory (FCT)- Abuja, Nigeria. The date palm shell was obtained from Keffi in Nassarawa State while the palm kernel shells were obtained from Ugbokolo in Benue State, Nigeria. Sampling period spans May-July 2004. The samples were sun dried and stored in plastic containers.

The respective samples were burnt in air tight containers for one hour each to obtain the corresponding charcoal. These were then stored in separate plastic containers. Each of the charcoal was ground in a mortar to powdered form and the resulting carbon sieved to obtain a particle size of $<124$ microns.

All reagents used in this research are of analytical grades. Pye Unicam 969 Flame Atomic Absorption Spectrophotometer, Mettler PC 400 weighing machine. Standard solutions of $\mathrm{Cu}, \mathrm{Mg}$ and $\mathrm{Pb}$ were prepared in the laboratory with concentration of $2 \mathrm{~g} / 100$ $\mathrm{cm}^{3}$ each.

\section{Method}

A $5.00 \mathrm{~g}$ each of the charcoals (adsorbent) was weighed and placed in three separate beakers and labeled. A $25 \mathrm{~mL}$ of each of the standard solution prepared was pipetted into each of the adsorbents with thorough stirring and allowed for a contact time of 6 hours. It was then filtered and the filtrates collected into clean plastic containers and stored. Room temperature and pressure conditions were employed. The procedure was repeated, but the contact time was adjusted to 2 hours at room temperature and pressure. The filtrate was then subjected to analysis by flame atomic absorption spectrophotometer. To ensure reproducibility of results, the analysis was carried out in triplicates.

\section{RESULTS AND DISCUSSION}

The results of the analysis of the filtrate by FAAS for $\mathrm{Cu}, \mathrm{Mg}$, and $\mathrm{Pb}$ at a contact time of 6 hours and 2 hours are shown in Tables 1 and 2 respectively. The amount of $\mathrm{Cu}, \mathrm{Mg}$ and $\mathrm{Pb}$ adsorbed was obtained from the difference in the filtrate and standard samples. This is recorded in Tables 3 and 4 for 6 hours and 2 hours contact time respectively. 
From the results as shown in Tables 5 and 6 above, the percentage recoveries for $\mathrm{Cu}$ are $80.99 \%, 82.26 \%$ and $83.06 \%$ for coconut shell charcoal, date palm shell charcoal and palm kernel shell charcoal respectively. In comparison to the $\%$ recovery in Table 6 , the recovery was higher for $\mathrm{Cu}$ with a contact time of 2 hours than at 6 hours. The reasons may be attributed to temperature fluctuations since room temperature was employed in the adsorption process (Inukai et al., 2004). Thermal stability plays an important role in the adsorption process. The observed \% recoveries are $82.72 \%, 83.35 \%$ and $83.98 \%$ respectively for coconut shell charcoal, date palm shell charcoal and palm kernel shell charcoal. This results also indicates that the palm kernel shell charcoal had the highest adsorption for $\mathrm{Cu}$ followed by the date palm shell charcoal and the coconut shell charcoal.

For $\mathrm{Mg}$ adsorption, the $\%$ recoveries in Table 5 are $99.10 \%, 99.11 \%$ and $99.11 \%$ for coconut shell charcoal, date palm shell charcoal and palm kernel shell charcoal respectively. The observed recoveries in Table 6 (contact time of 2 hours) are $99.16 \%$, $99.16 \%$ and $99.17 \%$ for coconut shell charcoal, date palm shell charcoal and palm kernel shell charcoal respectively. This however represents a higher recovery than that in Table 5. Pore spaces, particle size and thermal stability may be responsible for this variation. It was also observed that palm kernel shell charcoal had a higher percentage recovery than the coconut and date palm shell charcoals.

Adsorption of $\mathrm{Pb}$ on the three charcoals was higher than that of $\mathrm{Cu}$ and $\mathrm{Mg}$. In Table 5 the observed \% recovery are $99.96 \%, 99.98 \%$ and $100 \%$ respectively for coconut, date palm and palm kernel shell charcoals. The result in Table 6 is similar to that in Table 5 with recoveries of $99.99 \%$, $99.98 \%$ and $100 \%$ respectively for coconut, date palm and palm kernel shell charcoals. However, a contact time of 2 hours showed a higher percentage recovery than a contact time of 6 hours. Factors such as molecular size of $\mathrm{Pb}$, Pore sizes and variations in tropical temperature and pressure may plausibly be responsible for these high recoveries.

The results of the statistical analysis are shown in Tables 7, 8 and 9.

Table 1: Results of filtrate analysis for a contact time of 6 hours.

\begin{tabular}{lccc}
\hline Sample & \multicolumn{3}{c}{ Parameters (ppm) } \\
\cline { 2 - 4 } & $\mathbf{C u}$ & $\mathbf{M g}$ & $\mathbf{P b}$ \\
\hline Coconut shell charcoal & $3801.857 \pm 0.003$ & $181.167 \pm 0.001$ & $8.825 \pm 0.002$ \\
Date palm shell charcoal & $3548.262 \pm 0.001$ & $179.410 \pm 0.001$ & $4.674 \pm 0.002$ \\
Palm kernel shell charcoal & $3388.984 \pm 0.006$ & $179.488 \pm 0.003$ & $1.136 \pm 0.003$ \\
\hline
\end{tabular}

Table 2: Results of filtrate analysis for a contact time of 2 hours.

\begin{tabular}{lccc}
\hline Sample & \multicolumn{3}{c}{ Parameters (ppm) } \\
\cline { 2 - 4 } & $\mathbf{C u}$ & $\mathbf{M g}$ & $\mathbf{P b}$ \\
\hline Coconut shell charcoal & $3457.380 \pm 0.006$ & $168.909 \pm 0.001$ & $2.183 \pm 0.001$ \\
Date palm shell charcoal & $3329.946 \pm 0.001$ & $168.844 \pm 0.003$ & $3.924 \pm 0.003$ \\
Palm kernel shell charcoal & $3204.120 \pm 0.004$ & $167.538 \pm 0.001$ & $0.557 \pm 0.001$ \\
\hline
\end{tabular}


Table 3: Amount of $\mathrm{Cu}, \mathrm{Mg}$ and $\mathrm{Pb}$ adsorbed for a contact time of 6 hours.

\begin{tabular}{lccc}
\hline Sample & \multicolumn{3}{c}{ Parameters $\left(\mathbf{g} / \mathbf{1 0 0} \mathbf{~ c m}^{\mathbf{3}}\right)$} \\
\cline { 2 - 4 } & $\mathbf{C u}$ & $\mathbf{M g}$ & $\mathbf{P b}$ \\
\hline Coconut shell charcoal & 1.6198 & 1.9819 & 1.9991 \\
Date palm shell charcoal & 1.6452 & 1.9821 & 1.9995 \\
Palm kernel shell charcoal & 1.6611 & 1.9821 & 1.9999 \\
\hline
\end{tabular}

Table 4: Amount of $\mathrm{Cu}, \mathrm{Mg}$ and $\mathrm{Pb}$ adsorbed for a contact time of 2 hours.

\begin{tabular}{lccc}
\hline \multirow{1}{*}{ Sample } & \multicolumn{3}{c}{ Parameters $\left(\mathbf{g} / \mathbf{1 0 0} \mathbf{~ c m}^{\mathbf{3}}\right)$} \\
\cline { 2 - 4 } & $\mathbf{C u}$ & $\mathbf{M g}$ & $\mathbf{P b}$ \\
\hline Coconut shell charcoal & 1.6543 & 1.9831 & 1.9997 \\
Date palm shell charcoal & 1.6670 & 1.9831 & 1.9996 \\
Palm kernel shell charcoal & 1.6796 & 1.9833 & 1.9999 \\
\hline
\end{tabular}

Table 5: Percent (\%) recovery for a contact time of 6 hours.

\begin{tabular}{lccc}
\hline Sample & \multicolumn{3}{c}{ Percent $(\%)$ recovery } \\
\cline { 2 - 4 } & $\mathbf{C u}$ & $\mathbf{M g}$ & $\mathbf{P b}$ \\
\hline Coconut shell charcoal & 80.99 & 99.10 & 99.96 \\
Date palm shell charcoal & 82.26 & 99.11 & 99.98 \\
Palm kernel shell charcoal & 83.06 & 99.11 & 100 \\
\hline
\end{tabular}

Table 6: Percent (\%) recovery for a contact time of 2 hours

\begin{tabular}{lccc}
\hline Sample & \multicolumn{3}{c}{ Percent $(\boldsymbol{\%})$ recovery } \\
\cline { 2 - 4 } & $\mathbf{C u}$ & $\mathbf{M g}$ & $\mathbf{P b}$ \\
\hline Coconut shell charcoal & 82.72 & 99.16 & 99.99 \\
Date palm shell charcoal & 83.35 & 99.16 & 99.98 \\
Palm kernel shell charcoal & 83.98 & 99.17 & 100 \\
\hline
\end{tabular}


Table 7: Paired Samples Statistics.

\begin{tabular}{llcccc}
\hline & & Mean & $\mathbf{N}$ & Std. Deviation & Std. Error Mean \\
\hline Pair 1 & $\mathrm{Cu}$ analysis for a contact time of 2 hours & $1.642033 \mathrm{E} 0$ & 3 & .0208313 & .0120270 \\
& $\mathrm{Cu}$ analysis for a contact time of 6 hours & $1.666967 \mathrm{E} 0$ & 3 & .0126500 & .0073035 \\
\hline Pair 2 & $\mathrm{Mg}$ analysis for a contact time of 2 hours & $1.982033 \mathrm{E} 0$ & 3 & .0001155 & .0000667 \\
& $\mathrm{Mg}$ analysis for a contact time of 6 hours & $1.983167 \mathrm{E} 0$ & 3 & .0001155 & .0000667 \\
\hline Pair 3 & $\mathrm{Pb}$ analysis for a contact time of 2 hours & $1.999500 \mathrm{E} 0$ & 3 & .0004000 & .0002309 \\
& $\mathrm{~Pb}$ analysis for a contact time of 6 hours & $1.999733 \mathrm{E} 0$ & 3 & .0001528 & .0000882 \\
\hline
\end{tabular}

Table 8: Paired Samples Correlations.

\begin{tabular}{llll}
\hline & N & Correlation & Sig. \\
\hline Pair $1 \mathrm{Cu}$ analysis for a contact time of 2 hours \& $\mathrm{Cu}$ analysis for a contact time of 6 hours & 3 & .992 & .083 \\
Pair $2 \mathrm{Mg}$ analysis for a contact time of 2 hours \& $\mathrm{Mg}$ analysis for a contact time of 6 hours & 3 & .500 & .667 \\
Pair $3 \mathrm{~Pb}$ analysis for a contact time of 2 hours \& Pb analysis for a contact time of 6 hours & 3 & .655 & .546 \\
\hline
\end{tabular}

Table 9: Paired Samples Test.

\begin{tabular}{|c|c|c|c|c|c|c|c|c|c|}
\hline & & \multicolumn{5}{|c|}{ Paired Differences } & \multirow[t]{3}{*}{$\mathbf{t}$} & \multirow{3}{*}{ df } & \multirow{3}{*}{$\begin{array}{l}\text { Sig. (2- } \\
\text { tailed) }\end{array}$} \\
\hline & & \multirow[b]{2}{*}{ Mean } & \multirow{2}{*}{$\begin{array}{c}\text { Std. } \\
\text { Deviation }\end{array}$} & \multirow{2}{*}{$\begin{array}{c}\text { Std. Error } \\
\text { Mean }\end{array}$} & \multicolumn{2}{|c|}{$\begin{array}{l}\text { 95\% Confidence } \\
\text { Interval of the } \\
\text { Difference }\end{array}$} & & & \\
\hline & & & & & Lower & Upper & & & \\
\hline Pair 1 & $\begin{array}{l}\mathrm{Cu} \text { analysis for a } \\
\text { contact time of } 2 \\
\text { hours }-\mathrm{Cu} \text { analysis } \\
\text { for a contact time of } \\
6 \text { hours }\end{array}$ & $-2.4933333 \mathrm{E}-2$ & .0084477 & .0048773 & .0459185 & .0039481 & -5.112 & 2 & .036 \\
\hline Pair 2 & $\begin{array}{l}\mathrm{Mg} \text { analysis for a } \\
\text { contact time of } 2 \\
\text { hours - } \mathrm{Mg} \text { analysis } \\
\text { for a contact time of } \\
6 \text { hours }\end{array}$ & $-1.1333333 \mathrm{E}-3$ & .0001155 & .0000667 & -.0014202 & -.0008465 & $17.000^{-}$ & 2 & .003 \\
\hline Pair 3 & $\begin{array}{l}\mathrm{Pb} \text { analysis for a } \\
\text { contact time of } 2 \\
\text { hours - } \mathrm{Pb} \text { analysis } \\
\text { for a contact time of } \\
6 \text { hours }\end{array}$ & $-2.3333333 \mathrm{E}-4$ & .0003215 & .0001856 & -.0010319 & .0005652 & -1.257 & 2 & .336 \\
\hline
\end{tabular}

\section{Conclusion}

It can be deduced from this work that palm kernel shell charcoal has a higher adsorption capacity than the coconut shell and date palm shell charcoals. The metals studied had various percentage recoveries in the three different charcoals. This variation was attributed to differences in their molecular size, thermal stability, pore sizes and surface area. It is a known fact that all these charcoals are waste products from their respective processing factories, thus palm kernel charcoal without further treatment and preparation may be utilized effectively in 
heavy metal recovery from industrial effluents. This however may serve as alternative to activated carbon.

\section{REFERENCES}

Chien YY, Khairut SNK, Halimaton H, Hanapi M. 2004. Gas adsorption capacity of metal oxide modified zeolite adsorbents. Proc. of the $18^{\text {th }}$ Symposium of Malaysian Chemical Engineers, 121-127.

Dončo B. 2004. Monolayer capacity and specific surface of microporous adsorbents. Bull. Chem. Technol. Macedonia, 23(1): 1-5.

Hsing-Cheng H, Mark JR, ASCE M, Massoud R, Shiaoguo C, Ramsay C. 2002. Mercury adsorption properties of sulfur-impregnated adsorbents. $J$. Environ. Engin., 128(11): 1080-1089.

Inukai Y, Tanaka Y, Matsuda T. 2004. Removal of boron (III) by $\mathrm{N}$ methylglucamine-type cellulose derivatives with higher adsorption rate. Anal. Chim. Acta, 511(2): 261-265.

Linqi S, Yushong Z, Binglin H. 1999. Novel composite adsorbent for adsorption of urea. Polym. Adv. Technol., 10: 69-73.

Mehmet EA. 2010. Modification methods for the enhancement of adsorption capacity of adsorbents: A review. J. Int. Environ. Application Sci., 5(3): 463469.

Mizota T. 1999. Zeolite-water heat-pump system for effective use of waste heat. Proc. $13^{\text {th }}$ IPCWS, Physical Chemistry of Aqueous System, Toronto, Canada.

Peiyuan L, Sujuan Z, Shuixia C, Qikun Z, Junjian P, Bingqing G. 2008. Preparation and adsorption properties of polyethylenimine containing fibrous adsorbent for carbon dioxide capture. $J$. Appl. Polym. Sci., 108: 3851-3858.

Rifaqat AKR, Fouzia R. 2010. Adsorption studies on fruits of Gular (Ficus glomerata): Removal of $\mathrm{Cr}$ (VI). $J$. Hazard. Mater., 181: 405-412.

Rifaqat AKR, Moonis AK, Fouzia R. 2010. Utilization of Fennel biomass (Foeniculum vulgari) a medicinal herb. Chem. Engin. J., 156: 106-113.

Slimane RB, Abbsasian J. 2000. Copperbased sorbents for. coal gas desulfurization at moderate temperatures. J. Ind. Eng. Chem. Res., 39: 1338.

Velu S, Ma X, Song C. 2002. Zeolite-based adsorbent for desulfurization of jet fuel by selective adsorption. Fuel Chem. Div. Preprints, 47(2): 447-448.

Wang Y, Liu J, Duo J, Yu Y. 2005. New method for the preparation of adsorbent with high adsorption capacity. Chinese Sci. Bull., 50(21): 2432-2435.

$\mathrm{Xu}$ X, Song C, Andresen JM, Miller BG, Scaroni AW. 2003. Preparation and characterization of novel $\mathrm{CO}_{2}$ "molecular basket" adsorbents based on polymer-modified mesoporous molecular sieve MCM-41. Micro. Meso. Mater., 62: 29-45.

Yao H, Shen Y, Yuan X, Zhou YM. 2010. Study on Gatifloxacin adsorption by sludge activated carbon. Proc. of the $4^{\text {th }}$ International Conference on Bioinformatics and Biomedical Engineering (ICBBE), Chengdu, 1-5.

Yavus Ö, Aydin AH. 2006. Removal of direct dyes from aqueous solution using various adsorbents. Polish J. Environ. Studies, 15(1): 155-161. 